\title{
Substorms in space: The correlation between ground and satellite observations of the magnetic field
}

\author{
R. L. McPherron, ${ }^{1}$ C. T. Russell, M. G. Kivelson, and P. J. Coleman, Jr. ${ }^{1}$ \\ Institute of Geophysics and Planetary Physics, University of California at Los Angeles, \\ Los Angeles, California 90024
}

(Received August 15, 1973.)

\begin{abstract}
Satellite studies of magnetospheric substorms are necessarily statistical since there are few properly instrumented satellites in space at any one time. To carry out these studies, one selects an ensemble of similar substorms, determines an origin for substorm time, and performs an ensemble average to eliminate noise. Similarity between different substorms can be determined from contour maps of midlatitude magnetic perturbations as a function of longitude and universal time. The origin of substorm time can also be determined from midlatitude perturbations and is usually taken as the beginning of the positive bay near midnight. Use of these techniques has led to a phenomenological model of magnetospheric substorms that includes a growth phase. The controversy over the existence of the growth phase is at least partially a consequence of differing definitions of the origin of substorm time. Use of auroral zone magnetograms often gives an earlier onset than midlatitude magnetograms. However, midlatitude onsets do appear to order satellite data systematically. In this paper we illustrate the discrepancy between these two onset times and show how midlatitude onsets order satellite data in agreement with the growth phase model. Three events of increasing complexity are considered. Each has been previously reported in the literature and later criticized. We speculate that a polar magnetic substorm begins when a pair of $X$ - and $O$-type neutral lines form on closed field lines within the plasma sheet. Subsequently, the midlatitude positive bay begins when magnetic merging first encounters open field lines in the lobe of the tail.
\end{abstract}

\section{INTRODUCTION}

It is generally accepted that the geomagnetic field undergoes significant changes during a magnetospheric substorm. For example, recent reviews of magnetic field changes in space during substorms include: Russell and McPherron [1973], McPherron et al. [1973], Akasofu [1972], McPherron [1972], and Rostoker [1972]. In fact, most recent theoretical work appears to be based on the assumption that magnetic field merging is responsible for magnetospheric substorms, e.g., Vasyliunas and Wolf [1973]. Until very recently, almost all studies of the magnetic field changes during substorms were based on ground observations alone [Akasofu, 1968]. Since 1967, however, satellite observations have begun to reveal the complex changes which occur within the magnetosphere during substorms [Heppner et al., 1967]. Subsequent work by

\footnotetext{
${ }^{1}$ Also Department of Planetary and Space Science.
}

Copyright (c) 1973 by the American Geophysical Union. many individuals has demonstrated that nearly all regions of the magnetosphere undergo significant field changes in a substorm. The time-history of these field changes throughout the magnetosphere is the main subject of this paper.

In the phenomenological model of the magnetospheric substorm we have previously proposed [McPherron et al., 1973; Russell and McPherron, 1973], there are three phases of a magnetospheric substorm: the growth phase, the expansion phase, and the recovery phase. This model differs from previous models of the auroral and polar magnetic substorm [Akasofu, 1968] in the inclusion of a growth phase. Such a growth phase is expected theoretically [Coroniti and Kennel, 1972b], but whether or not it can be observed experimentally is a question of considerable controversy [Vasyliunas and Wolf, 1973; Akasofu and Snyder, 1972; and Mozer, 1973].

In the definition of the growth phase made by McPherron [1970] auroral zone magnetograms were used to define an interval of weak magnetic disturbance prior to the sudden appearance of intense nega- 
tive bays at near-midnight stations. A wide variety of phenomena was found to occur during this interval and was proposed as precursory activity of an expansion phase to follow.

Recently, Akasofu and Snyder [1972] and Rostoker and Kisabeth [1973] have pointed out the inadequacies of the existing network of auroral zone observatories. They suggest that weak bays may be the effects of weak, distant, localized, or high latitude substorm expansions. However, Nishida and Nagayama [1973] and McPherron [1973] have argued that localized events in the auroral zone should be ignored, and for the purposes of organizing satellite data only events having a "global signature" should be used. In general, a global signature has been subjectively defined as the beginning of a bay seen at several widely distributed auroral zone stations within a time interval of $30 \mathrm{~min}$ or less, or a substorm evident as a positive bay onset at several midlatitude stations as well as in the auroral zone.

Using such global signatures of substorm onset, a number of investigators have developed a phenomenological model of the magnetospheric substorm, e.g., McPherron et al. [1973], and Nishida and Nagayama [1973]. In general, this model is in good agreement with theoretical suggestions by Coroniti and Kennel [1972a, b, 1973]. Recently, however, $A$ kasofu [1972] has exhaustively reviewed the evidence on which the phenomenological and theoretical models are based and concluded that expansion onsets were incorrectly determined. Using different definitions of expansion onsets for the same data, he derives a quite different phenomenological model.

In this paper we have reexamined several of the events previously reported by our group which have also been criticized by $A$ kasofu [1972]. We will show that some of this criticism is justified. In particular, we conclude that there is no simple one-toone relationship between polar magnetic substorms and magnetospheric substorms as defined by midlatitude magnetograms. It appears that in some cases polar magnetic substorms occur during the growth phase of a magnetospheric substorm.

It might be suggested that midlatitude magnetograms are an inappropriate measure of substorm onset and the concept of a growth phase is incorrect. However, as we will show, magnetospheric observations are more systematically organized by midlatitude onsets than by auroral zone onsets. In view of this fact, we prefer to retain the concept of the growth phase of a magnetospheric substorm and suggest that the association of auroral and polar magnetic substorms with the magnetospheric substorm requires further study.

\section{EXPERIMENTAL PROBLEM}

The experimental problem which has led to the controversy over the existence of a substorm growth phase requires some additional discussion. In order to establish the morphology of a substorm in space we must proceed statistically since we have only one or two satellites to work with at any one time. To do this, we usually make two assumptions: first, that all substorms are fundamentally similar and, second, that we can determine accurately some critical time in the substorm. If these assumptions are satisfied, we can select an ensemble of similar substorms with the satellite in a specified location. Knowing the onset time for each event, we can perform an ensemble average. The effects of noise inevitably present in geophysical data are reduced in the average, and the magnetospheric signature of a substorm emerges.

The foregoing situation is analogous to that in the laboratory when we trigger an oscilloscope off the signal and obtain a clear waveform. If we trigger with noise, however, we get a blurred waveform or an incorrect one.

\section{DETERMINATION OF ONSET TIMES}

Our current approach to the determination of onset times is summarized in Figure 1. We take the interval of time within which the magnetospheric event we are studying occurs and determine all possible substorm onsets. In the auroral zone these will be sudden enhancements of negative bays. At midlatitudes these are onsets of positive bays. Usually, if there is a clear onset at midlatitude, we choose this time as our reference time. If there are several onsets at midlatitudes, we choose the one after which the largest perturbation occurs. If there are no midlatitude onsets, we use the onset at the nearmidnight auroral zone station.

It should be pointed out that this definition of onset often ignores some features which may be earlier onsets of polar magnetic substorms. It should also be noted how easy it is to destroy any semblance of organization of the magnetospheric data if in successive substorms we were to choose the various onsets shown. An ensemble average of the magnetospheric data would average to nearly a straight line.

That this definition of substorm onset organizes some satellite data extremely well is demonstrated in 


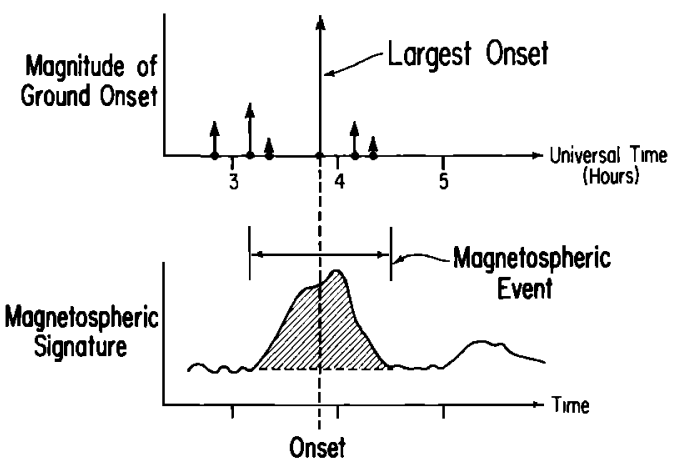

Fig. 1. Technique used in this study for obtaining origin of substorm time for correlation with magnetospheric data.

a companion paper by Caan et al. [1973]. Figure 2, taken from that paper, shows the magnetic energy density in the north lobe of the geomagnetic tail organized by the onset of midlatitude positive bays (flux return time). Clearly the lobe energy density increases prior to $t=0$ and decreases after.

\section{DETERMINATION OF SUBSTORM SIMILARITY}

As mentioned earlier, it is also important to be certain that substorms used in an ensemble average are similar. Figures 3, 4, and 5, taken from a companion paper by Clauer and McPherron [1973], show how we quantitatively characterize a given substorm. Figure 3 contains plots of the $H$ component of the magnetic field as observed at midlatitudes. A positive bay onset at the midnight station Honolulu at 1037 is emphasized by a vertical line. Delayed onsets at earlier local times are shown by arrows.

The information contained in the magnetograms is more conveniently displayed in the two contour maps of Figures 4 and 5. Figure 4 shows contours of magnetic perturbation as a function of position (local time) and time (UT). To obtain the perturbation, the quiet day at each station has been removed and the resulting variations normalized to the beginning of the event. This normalization is accomplished by subtracting the local time profile at the beginning of the event from all later local time profiles.

Information which can be obtained from these maps includes types of onset, onset time, local time of onset, local time of maximum development, extent in local time, and magnitude of the perturbation. As shown by Clauer and McPherron [1973], there is great variability in these parameters from one substorm to the next. For example, the event shown begins near midnight but appears to sweep westward reaching maximum development near 2000 LT. The magnetospheric signature of this substorm on the 0300 local time meridian should be quite different than would be the case if the event had swept eastward to $0300 \mathrm{LT}$.

In our opinion, the present confusion about the magnetospheric signature of substorms is as much a consequence of substorm variability as it is of inaccuracy in determination of onset times. This fact does not seem to have been previously recognized, as most criticism of our phenomenological model has been directed to the question of onset timing.

\section{PHENOMENOLOGICAL MODEL OF MAGNETIC VARIATIONS DURING MAGNETOSPHERIC SUBSTORMS}

In order to motivate our presentation of satellite data, we briefly summarize our current phenomenological model of the magnetic field variations during substorms. This model is presented schematically in Figure 6 for the growth and expansion phases. The growth phase begins when the solar wind magnetic field turns southward. It is seen in the lobes of the

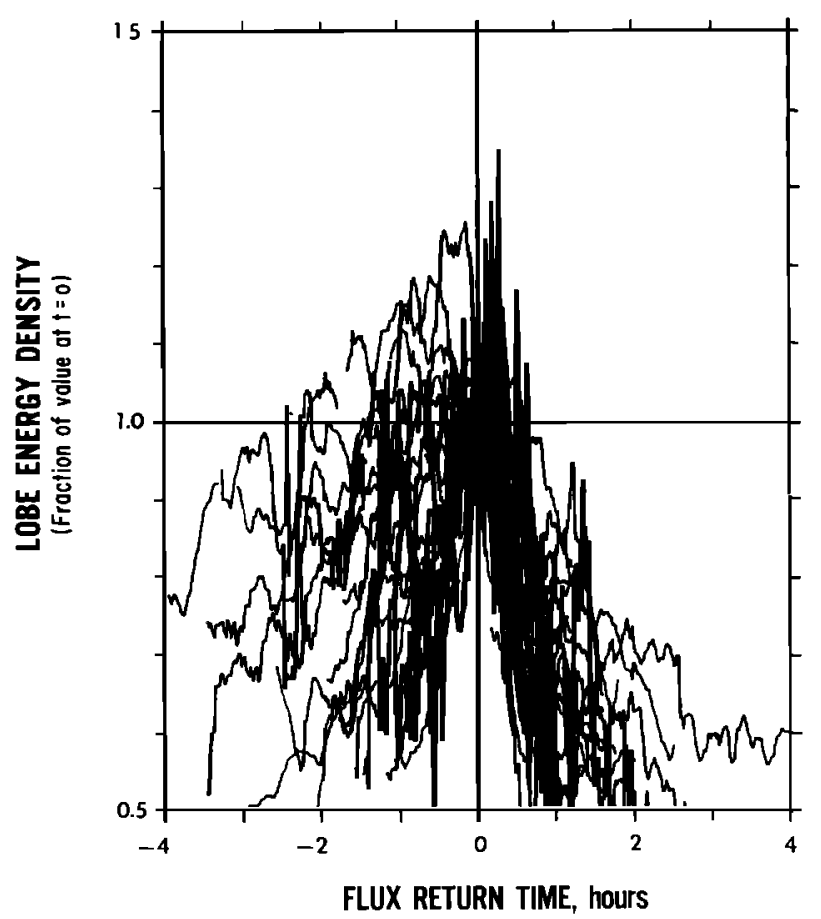

Fig. 2. Superposed epoch analysis of magnetic energy density fluctuations in lobe of tail, 24 events in 1968. Time origin defined as in Figure 1, primarily on the basis of midlatitude magnetograms. 


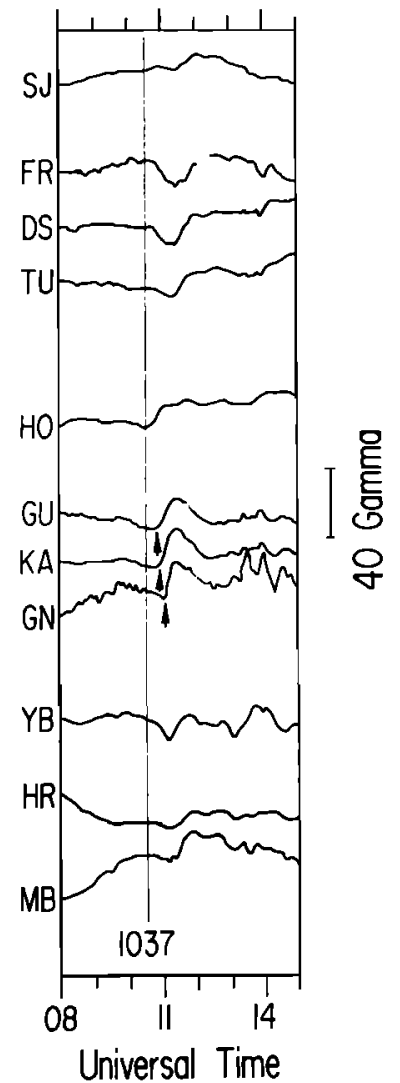

Fig. 3. Westward motion during a multiple onset substorm, February 17, 1967: $H$ component midlatitude magnetograms.

tail as a gradual increase in the magnetic energy density. At synchronous orbit and midlatitudes it is seen as a gradual depression in the horizontal component of the earth's field. In the auroral zone, weak positive and negative bays are seen. Although not shown in the diagram, erosion of the dayside magnetopause and thinning of the plasma sheet are also growth phase phenomena.

During the expansion phase the energy density in the lobe of the tail decreases. At synchronous orbit and midlatitude near midnight there is a rapid increase in the magnetic field, while at dusk there is a further rapid decrease. In the auroral zone there is a sudden enhancement in the bay disturbances, particularly in the negative bay near midnight. In addition, during the expansion phase the plasma sheet expands.

While this model may be adequate for isolated substorms or the first substorm after a period of quiet, for the majority of substorms circumstances are usually more complex. For example, in some cases a negative bay may begin suddenly in the auroral zone long before the midlatitude and magnetospheric changes characteristic of our expansion phase. In other cases when the satellite is in the tail lobe far from the central meridian of a substorm, there are time delays which indicate that some substorms are more localized than suggested by our idealized model.

Despite problems such as these, we feel that our present model can, with minor modifications, organize data for a majority of substorms. In the data presentation which follows we begin with an event which appears to fit this model almost perfectly. We then consider several events previously reported in the literature and which have been criticized by Akasofu [1972]. We show that this criticism is justified on the basis of auroral zone magnetograms, but, for these events, the midlatitude magnetograms still organize the magnetospheric data in the way predicted by our model.

\section{A SIMPLE EVENT, FEBRUARY 25, 1967}

An example of a magnetospheric substorm which appears to follow exactly the morphology outlined above occurred on February 25, 1967. This event was originally chosen by McPherron [1970] as an example of a substorm with obvious growth phase. Recently, Meng and Colburn [1973] have also examined tail data during this event. Reexamination

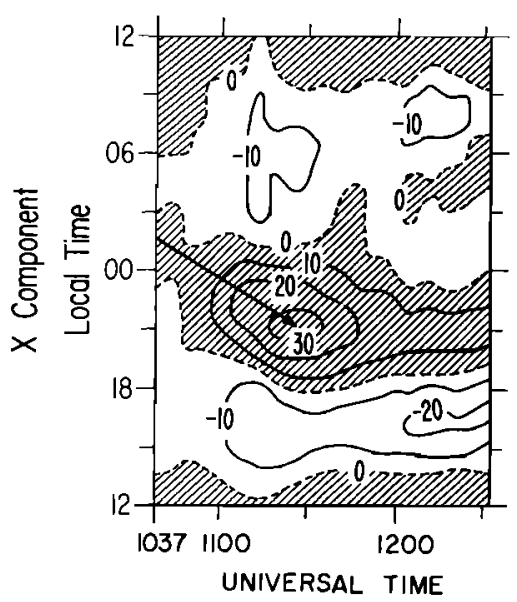

Fig. 4. Midlatitude map with quiet day variations removed, normalized to onset at $1037 \mathrm{UT}$, February 17, 1967: magnetic perturbation as a function of position and time. 


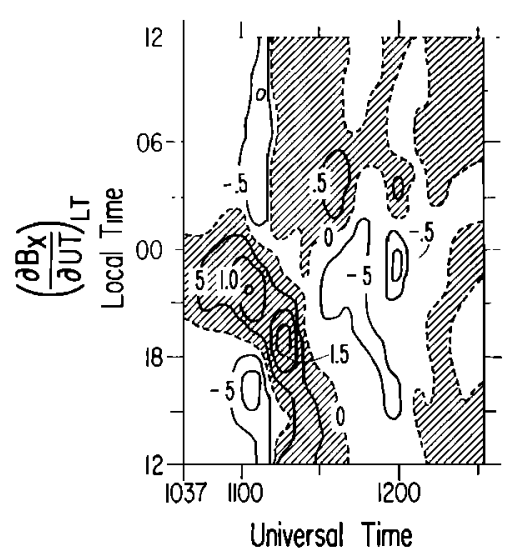

Fig. 5. Midlatitude map with quiet day variations removed, normalized to onset at $1037 \mathrm{UT}$, February 17, 1967: $\left(\partial B_{X} / \partial \mathrm{UT}_{\mathrm{LT}}\right.$ versus Universal Time.

of this event with a more complete data set makes the previous arguments even more persuasive.

Solar wind dynamic pressure and electric field for February 25, 1967, are plotted at the top of Figure 7. At the beginning of this day Explorer 33, on which these measurements were made, was located far upstream of the earth at a position in solar magnetospheric (GSM) coordinates of $(55.8,-20.1,-16.7)$ $R_{E}$. At the bottom of the figure the $A E$ index based on stations in the western sector has been plotted. The event of interest began at Explorer 33 at about 0320 with a simultaneous decrease

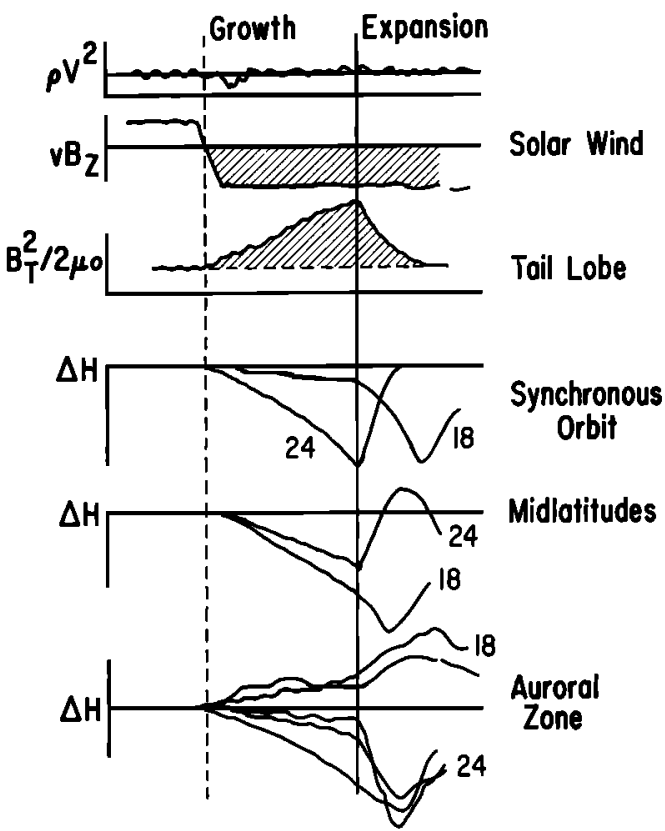

Fig. 6. Phenomenological model of magnetic variations during magnetospheric substorms which is supported by data presented in subsequent figures.

in solar wind dynamic pressure and a southward turning of the magnetic field. No immediate effects of either of these phenomena were seen in the auroral zone at the expected arrival time $11 \mathrm{~min}$ later. However, after a further 15 min delay, mag-

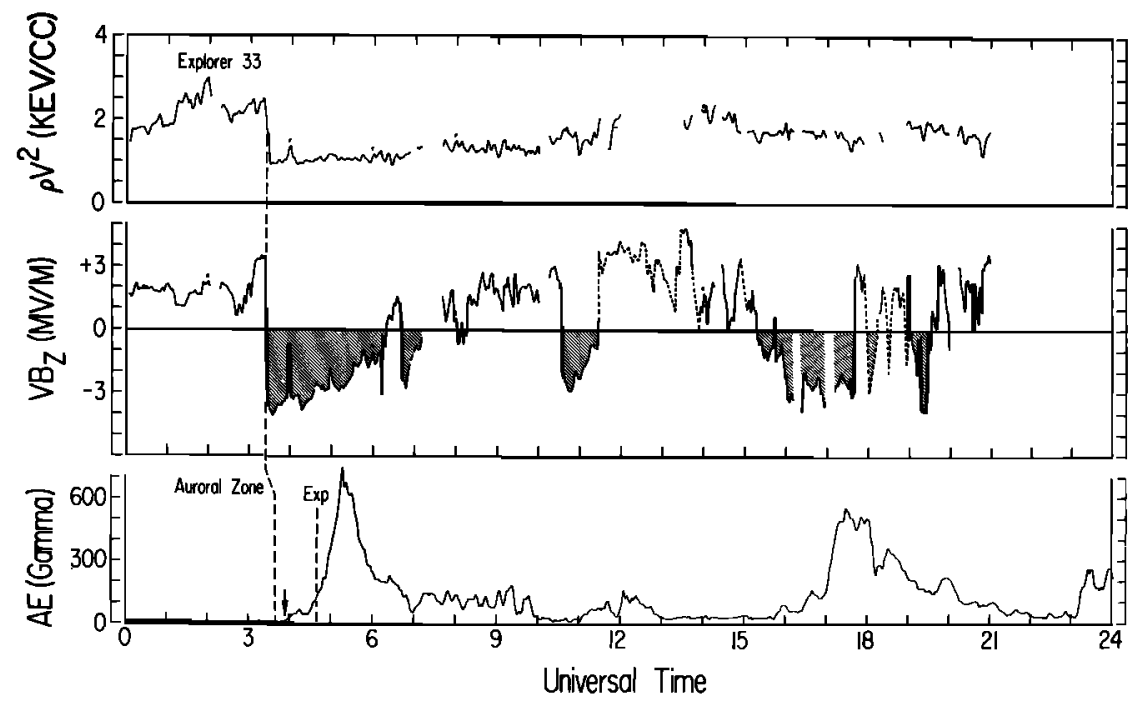

Fig. 7. Solar wind dynamic pressure and electric field at Explorer 33 well upstream from the earth, and the response of the auroral electrojet on February 25, 1967. 
netic activity began to appear gradually. After about $1 \mathrm{hr}$ of such weak activity, there was a clear onset near midnight of a polar magnetic substorm. Subsequently, there was a large, rapid increase in $A E$.

The auroral zone and midlatitude magnetograms for this day are displayed in Figure 8. Solar wind $\boldsymbol{B}_{z}$ is shown for reference. Traces of the horizontal component have been superimposed such that all traces pass through a common point at the expected arrival time of the solar wind discontinuity. Beginning at the expected time was a negative sudden impulse ( $-\mathrm{Si}$ ) of 10 to $15 \gamma$ magnitude apparent at midlatitudes. Although we cannot be absolutely certain, we assume that the southward turning which was coincident with the pressure decrease at Explorer 33 was also coincident at the magnetopause, i.e., it arrived with the $-S i$. Subsequent to the $-S i$ and in

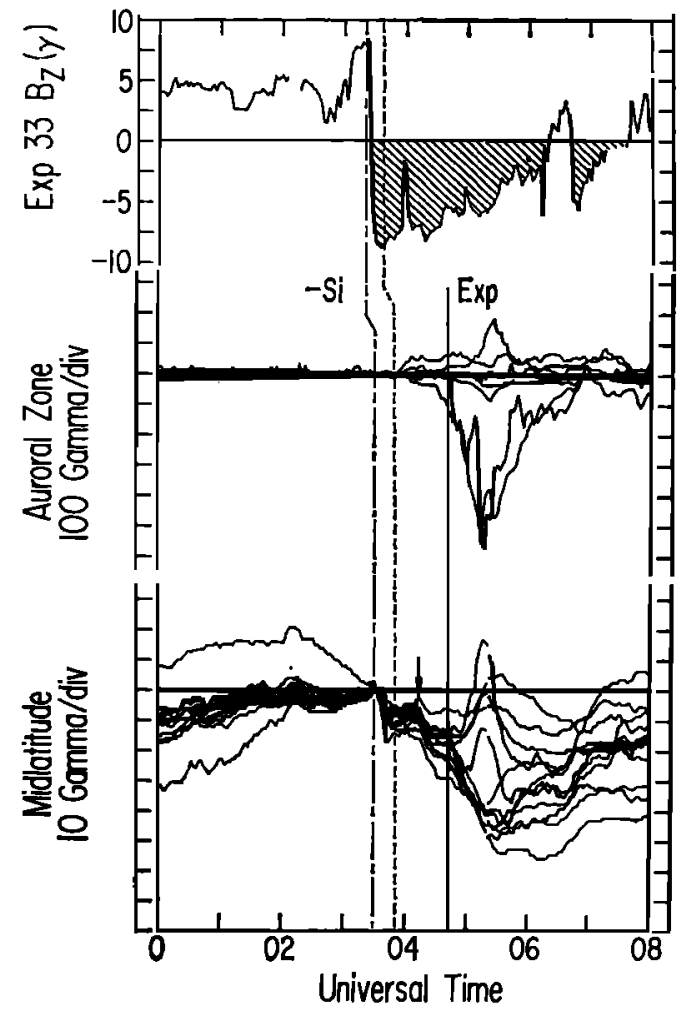

Fig. 8. Auroral zone and midlatitude magnetograms showing north-south component variations in response to the solar wind on February 25, 1967. Traces are superimposed to pass through a common point at the expected arrival time of the solar wind discontinuity at earth. EXP is time of simultaneous onset at midlatitudes and in the auroral zone of the substorm expansion phase (0440 UT). conjunction with the weak activity in the auroral zone, the $H$ component at midlatitudes decreased. This decrease continued at all stations until the onset of the substorm expansion at the midnight station in the auroral zone. Simultaneously, the midnight stations at midlatitudes observed the onset of a positive bay. Following the expansion onset, midlatitude stations near dusk recorded a further rapid decrease in the $H$ component.

To illustrate the nature of the midlatitude magnetic perturbations of this substorm, we have prepared contour maps similar to those described in a previous section. Figure 9 contains a map of the dipole, north-south component. The substorm expansion is evident as a set of nested contours centered about $1.6 \mathrm{hr} \mathrm{LT}$ and $0515 \mathrm{UT}$. Also evident in this plot is a large depression roughly centered about dusk.

At the top of the figure several parameters derived from the contour have been plotted. These include the maximum, average, and minimum magnetic perturbations seen anywhere around the earth at each universal time. The average has been labeled $D s t$ since this is its more familiar designation. It is obvious that Dst does not reflect the complexity of midlatitude magnetic variations during substorms. However, the maximum and minimum respectively show changes near midnight (increases) and near dusk (decreases). From the data shown it can be seen that a decrease in the north-south component began at some local time shortly after the - Si (about 0350 ) and was in progress everywhere by 0412 .

The actual onset time of the midlatitude positive bay is not obvious in this figure because of finite quantization imposed by our choice of contour levels. In Figure 10, however, we have plotted contours of the rate of change of the $X$ component in which extrema are evident as zero contours (dashed lines). The onset near midnight at 0440 is apparent as a change from negative to positive slope (shaded). Figure 11 shows contours of perturbation in the east component. It is clear that east-west perturbations characteristic of field-aligned currents began at 0440. The fact that no effects were seen in the east component prior to this time may indicate that no strong field-aligned currents are associated with the initial growth phase depression at the earth's surface.

Magnetic changes in the lobe of the geomagnetic tail are presented in Figure 12. This figure is taken from a recent paper by Meng and Colburn [1973]. The $-S i$ was seen as an $8-\gamma$ decrease in the lobe 
field. Subsequently, and in conjunction with the southward solar wind magnetic field, the lobe field increased by $6 \gamma$. At 0440 , the onset of the substorm expansion, the lobe field began to decrease.

The event of February 25, 1967, presented in the preceding figures serves as a prototype of our phenomenological model of magnetic variations during substorms. We have referenced all times to what we have called the onset of the substorm expansion. This onset was determined from both auroral zone and midlatitude magnetograms which agree within the accuracy of the original data $(\simeq 2 \mathrm{~min})$. We cannot rule out the possibility that the substorm expansion actually began earlier than suggested by the midnight auroral zone station (Great Whale River). However, it is unlikely that any serious error exists in the midlatitude determination. Consequently, we conclude that this substorm is a good example of the morphology predicted by our phenomenological model.

It has been pointed out by a referee of this paper that since the southward turning was accompanied by a decrease in pressure, it is inappropriate to call this event simple. However, we have been unable to find a "simpler" event with this amount of collaborative data. In our defense we note that there has been no demonstration that sudden impulses cause substorms when the field has not been previously southward. Consequently, we assume the effects of the $-S i$ are linearly superposed on those of the southward field.

\section{A COMPLEX EVENT, FEBRUARY 13, 1968}

Most substorms are more complex than the event discussed above. Several good examples of more complicated substorms occurred on February 13, 1968. These events were first discussed by Fairfield and Ness [1970]. More detailed analysis was carried out by Aubry and McPherron [1971], and recently by Hones et al. [1973]. Akasofu [1972] has criticized this detailed analysis, drawing quite different conclusions. The basis of the controversy over the interpretation of these events can be understood from the data in Figure 13. The top two panels show solar wind dynamic pressure and electric field at Explorer 33. The satellite was located at GSM position $(64,-11,-41) R_{E}$ well upstream of the earth. The $A E(10)$ index for this day is shown in the middle panel. The bottom panel shows, respectively, the asymmetry $(A S Y M)$ index, maximum,

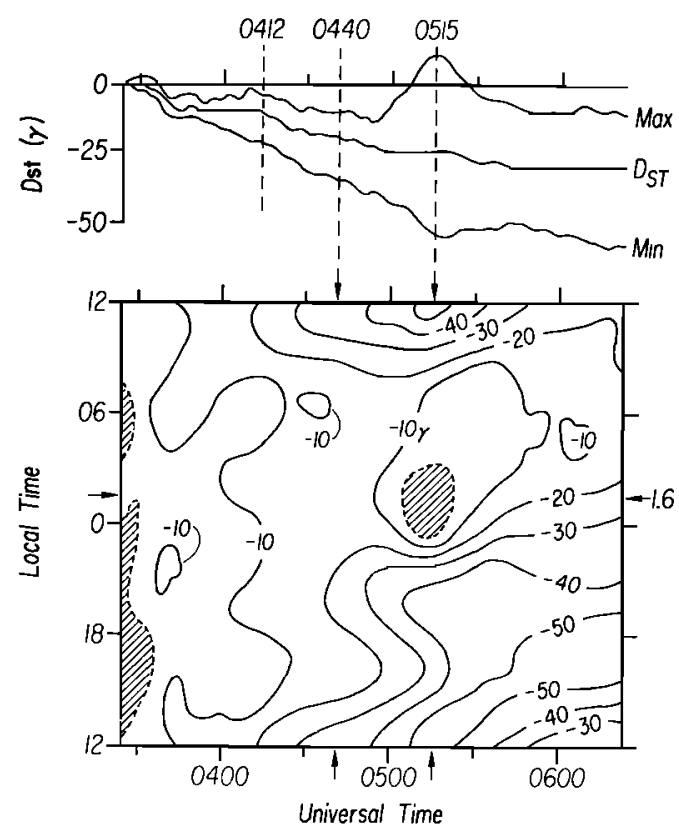

Fig. 9. Contour map of midlatitude magnetic perturbations in north-south component associated with expansion onset of 0440 UT, February 25, 1967. Also, maximum, average ( $D s t)$, and minimum local time time profile as a function of universal time.

average (Dst), and minimum of the midlatitude local time profile of the north-south component.

The last two vertical dashed lines show the approximate substorm onset times (1220 and 1610)

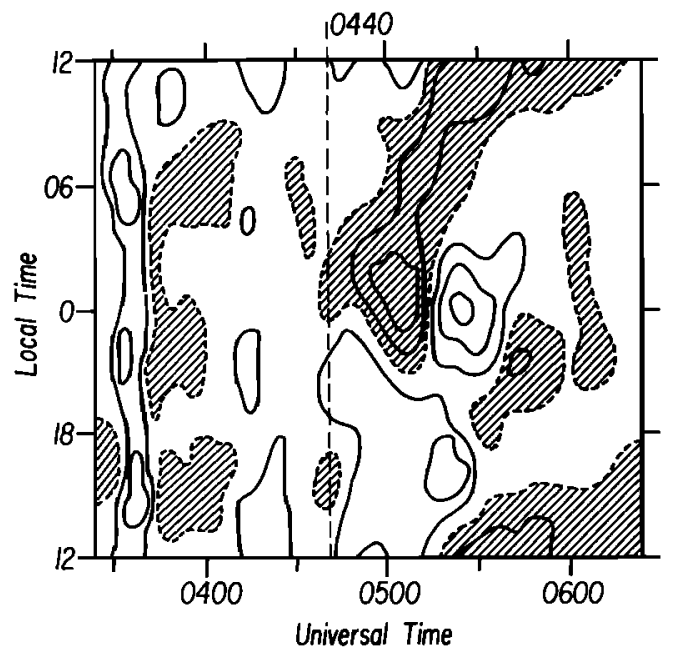

Fig. 10. Contour map of the derivative of the north-south component for the 0440 substorm of February 25, 1967. The shading represents positive values and dashed lines, the zero contour. 


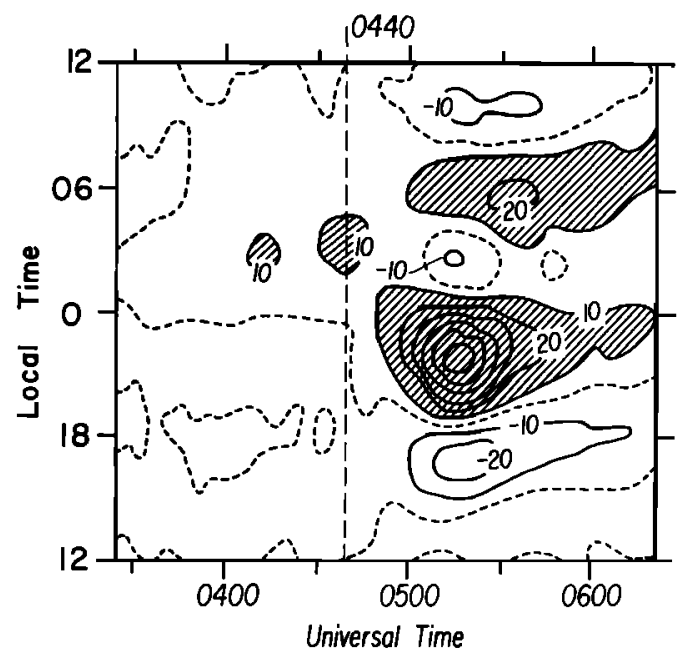

Fig. 11. Contour map of the east-west component for the 0440 substorm of February 25, 1967. The shading represents positive values and dashed lines, the zero contour.

used by Aubry and McPherron [1971]. From the bottom panel it is apparent that the times of these lines correspond to the beginning of midlatitude positive bays (see trace of maximum). Examination of the $A E$ index relative to these lines shows that auroral zone magnetic activity began well before the times originally chosen by Aubry and McPherron. Akasofu [1972] has argued that the growth phases identified by Aubry and McPherron prior to these substorm onsets are actually effects of the expansion phase of polar magnetic substorms.

The auroral zone magnetograms from which the $A E$ index was constructed are plotted in Figure 14 . The top panel repeats $A E(10)$. Successive traces down the figure are the observations made at each of the 10 stations used in $A E$ determination. Traces are organized by west longitude with midnight roughly along a diagonal. Features in the magnetograms which may correspond to onsets of expansion phases have been indicated by stars above the trace. If a feature is evident at two or more stations, a vertical dashed line has been drawn.

The features identified by $A$ kasof $u$ [1972] as expansion onsets are at 1100 and 1545 UT, which should be compared to 1220 and 1610 as shown in Figure 13. Examining the last event first, we see that the earliest sharp onset in the auroral zone is at College (CO) and Cape Wellen (CW). At this universal time $(1600)$ both stations are close to the dawn meridian. As a consequence, it is unclear what the meaning of the sudden development of a negative bay corresponds to. We do note that the midnight stations Cape Cheyluskin (CC) and Dixon Island (DI) do not see the beginning of a sharp decrease until about 1610. However, it is quite clear that auroral zone magnetic activity did begin rather suddenly sometime before the time chosen by Aubry and McPherron.

The situation for the earlier event is more complicated. It is obvious that a weak event did begin about 1115 UT and that a second, and much larger, event began at $1200 \mathrm{UT}$. The midnight station College (CO), however, shows a more or less continuous decrease in $H$ suggesting this was a single event. Again, it is quite apparent that auroral zone activity began long before the time chosen by Aubry and McPherron.

Midlatitude magnetograms from which Aubry and

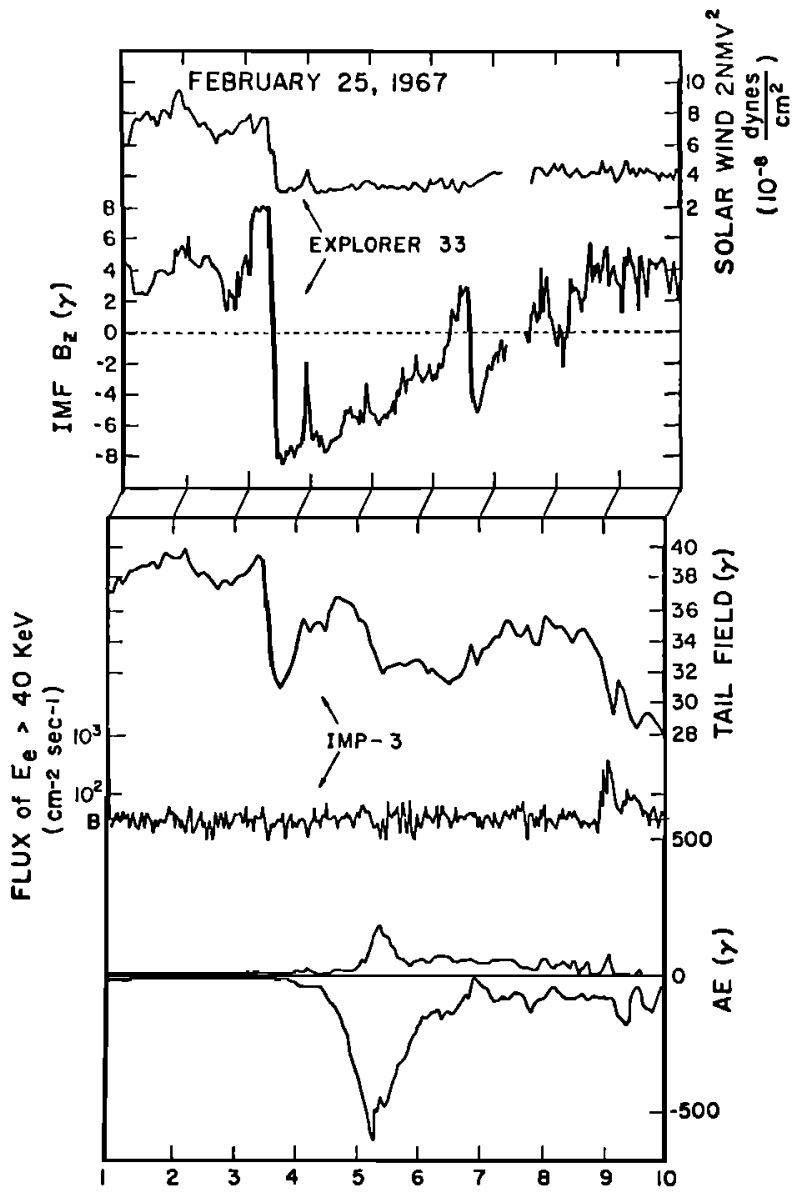

Fig. 12. Magnetic field observations in the geomagnetic tail on February 25, 1967. Figure taken from paper by Meng and Colburn [1973]. 


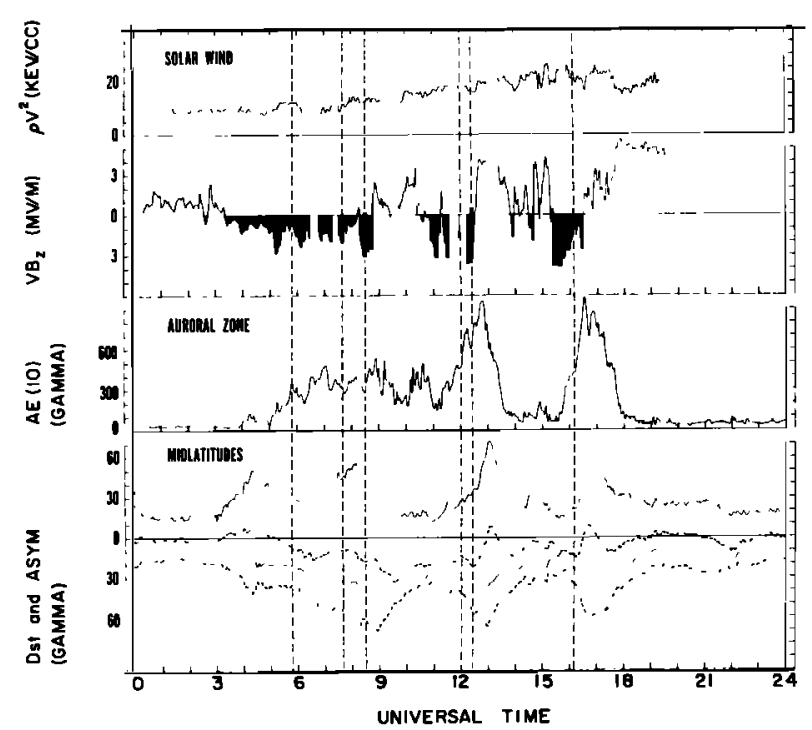

Fig. 13. Solar wind dynamic pressure and electric field at Explorer 33, $A E$ index, asymmetry, maximum, average $(D s t)$, and minimum of local time profile of the $H$ component at midlatitudes on February 13, 1968. Vertical dashed lines are midlatitude determinations of the origin of substorm time.

McPherron determined onsets are shown in Figure 15. The format of this figure is the same as just described with stars indicating possible onsets of positive bays near midnight. Two vertical dashed lines are drawn at 1200 and 1545 corresponding to possible onsets in the auroral zone, as just discussed. At this time there is a weak increase at Honolulu (HO) at the dawn meridian. However, significant, widespread activity did not begin until 1610 . At this time the midnight stations Gnangara (GN) and Kakioka (KA) recorded the onset of a positive bay. For this case there is a clear discrepancy between the sudden onset of a negative bay in the auroral zone and the beginning of the midlatitude positive bay.

The earlier substorm event is also more complicated at midlatitudes. Examining the magnetograms, we find no evidence of a positive bay beginning about 1115 . At 1200 , however, the midnight station Honolulu (HO) observed the beginning of a positive bay. Near dawn (Tucson, TU) this event was seen as a gradual onset. It is important to note, though, that most of the increase both at midnight and near dawn was not seen until after 1240 . This event is very similar to the one discussed earlier (see discussion of Figures 3, 4, and 5) in which the disturbance appeared to begin near midnight and sweep westward

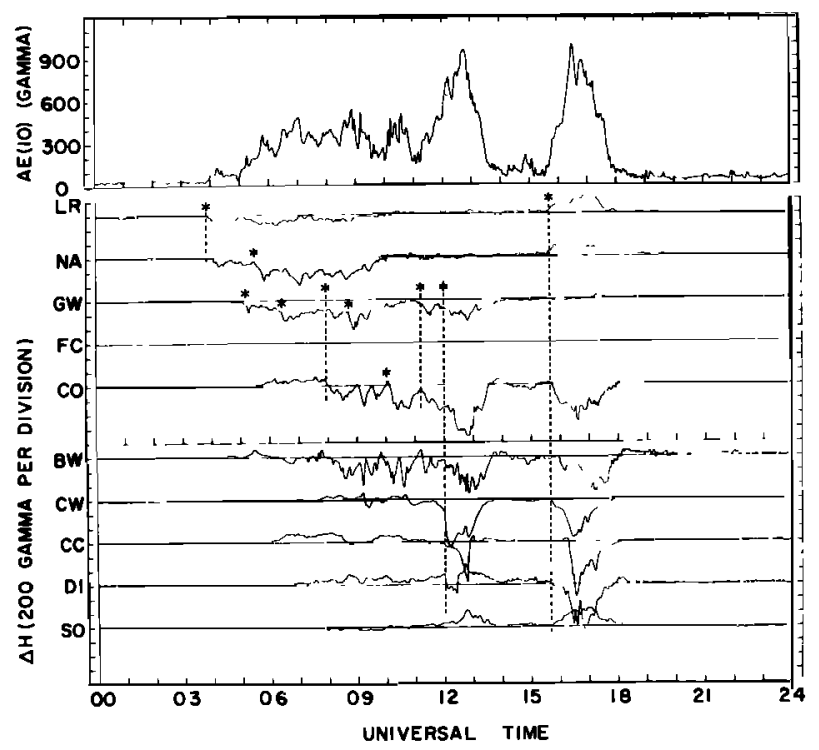

Fig. 14. $A E$ index and $H$ component at various auroral zone observatories on February 13, 1968. Stations are arranged by progressive west longitude. Possible expansion onsets are indicated by stars and vertical dashed lines.

toward dusk. For the 1200 event of February 13, 1968, the event appears to begin near midnight and sweep eastward toward dawn.

Contour maps substantiating our interpretation of

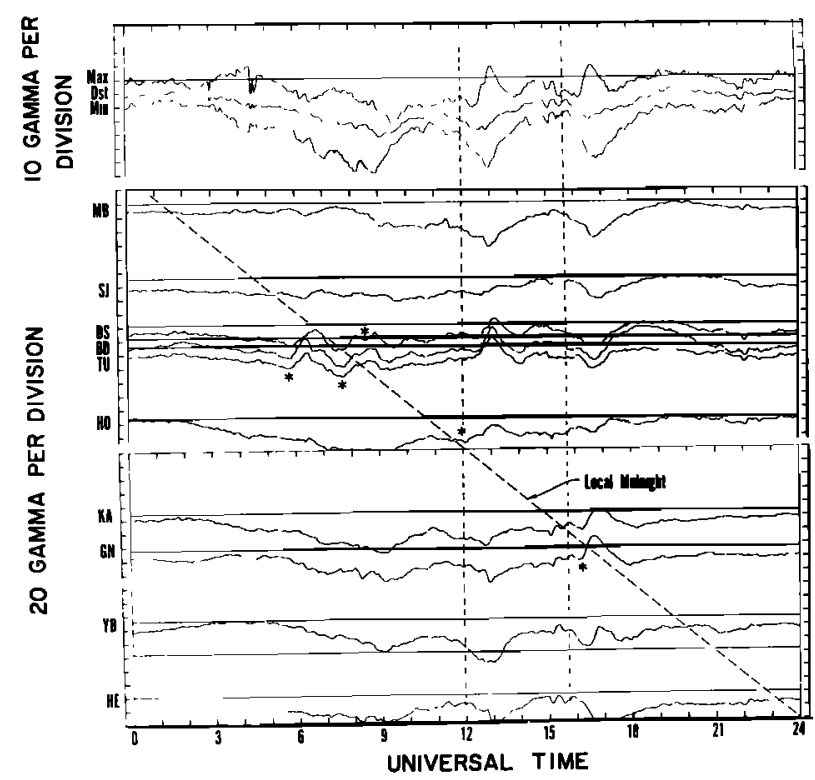

Fig. 15. North-south component deviations from quiet day at midlatitudes on February 13, 1968. Also shown as a function of universal time are maximum, average, and minimum deviations seen at any local time. Stars indicate possible midlatitude onsets of positive bays. Vertical dashed lines are times of two auroral zone onsets taken from Figure 14. 
the magnetograms for the 1610 event are shown in Figures 16 and 17. It is obvious from the derivative map that 1610 is the appropriate beginning of the midlatitude positive bay. Equally evident in the map of the north-south component is the gradual depression at dusk beginning before the onset of the positive bay. Also, a rapid decrease follows the onset. Similar maps were made for the earlier event. The additional complexity of this event is reflected in the maps. Our interpretation of this event, presented in the discussion of Figure 15, was derived from these maps.

Magnetic variations in space on February 13, 1968 , are presented in Figure 18. The top panel shows data at ATS 1 in synchronous orbit (midnight $10 \mathrm{UT}$ ). The bottom panel shows the field at Explorer 34 approximately $25 R_{E}$ behind the earth and $10 R_{E}$ toward the dawn side of the tail. Our interpretation of possible substorm onsets is shown along the dashed horizontal lines. Solid diamonds refer to weak events, while solid circles with arrows refer to stronger events. In this paper we consider only the substorms at 1200 and 1600.

Pronounced increases in the magnetic energy density of the tail lobe are apparent during both substorms. The times chosen by Aubry and McPherron, 1220 and 1610 , correspond very closely to the beginning of decreases in the lobe field. Earlier possible times, for example 1545,1200 , or 1115 , do not correspond in any systematic way with the lobe

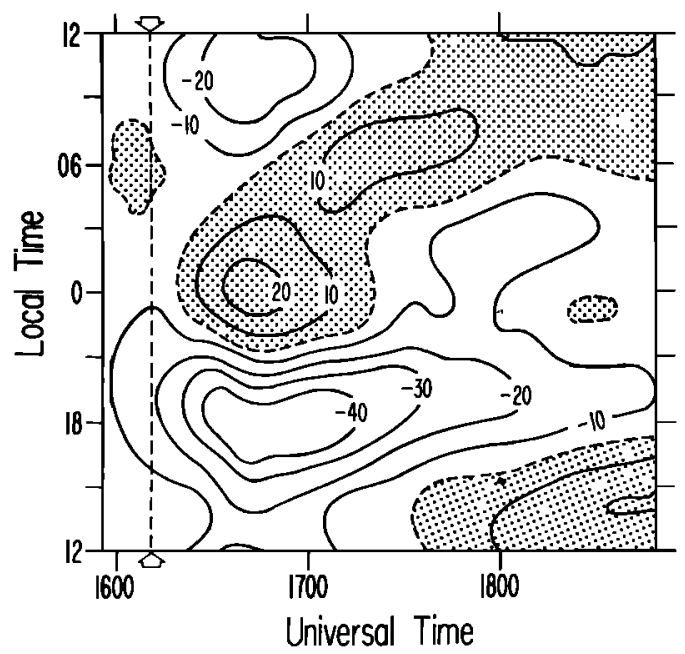

Fig. 16. Contour map of the north-south component for the 1610 substorm expansion on February 13, 1968. The shading represents positive values and dashed lines are zero contours.

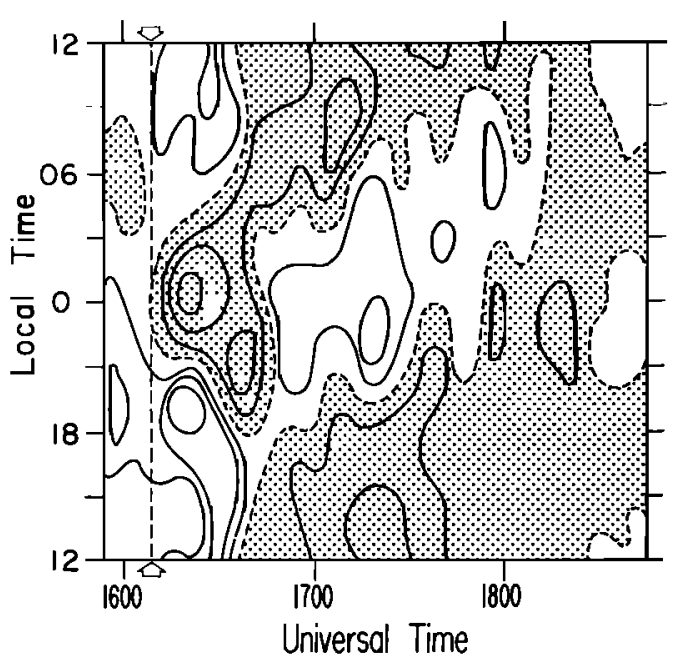

Fig. 17. Contour map of the derivative of the north-south component for the 1610 substorm expansion on February 13, 1968. The shading represents positive values and dashed lines are zero contours.

field. Also, we note that for the 1200 substorm during which ATS 1 was located just past midnight, the $H$ component does not begin to recover until about 1220.

Also shown in Figure 18 by vertical dashed lines are intervals of continuously southward solar wind magnetic field. For the 1200 event there is good agreement between the field and an increase in the lobe energy density. For the 1600 event the agreement is not so persuasive unless we include the interval of fluctuating solar wind field (see Figure 13). We note that for this event, we have no means of precisely determining the arrival time of the southward field at the magnetopause. As discussed originally by Aubry and McPherron [1971], it is reasonable to assume that the solar wind convection time is a good estimate of the delay.

These two substorms on February 13, 1968 clearly illustrate the complexity of typical substorms and should be contrasted to the simpler event of February 25,1967 , which served as our prototype. Nonetheless, by using the beginning of a major increase in the horizontal component at midlatitudes we find the observations are in agreement with those of February 25, 1967, and also with our phenomenological model. We note, however, that to obtain agreement we have ignored certain events in the auroral zone which may be interpreted as the onset of substorm expansions. 


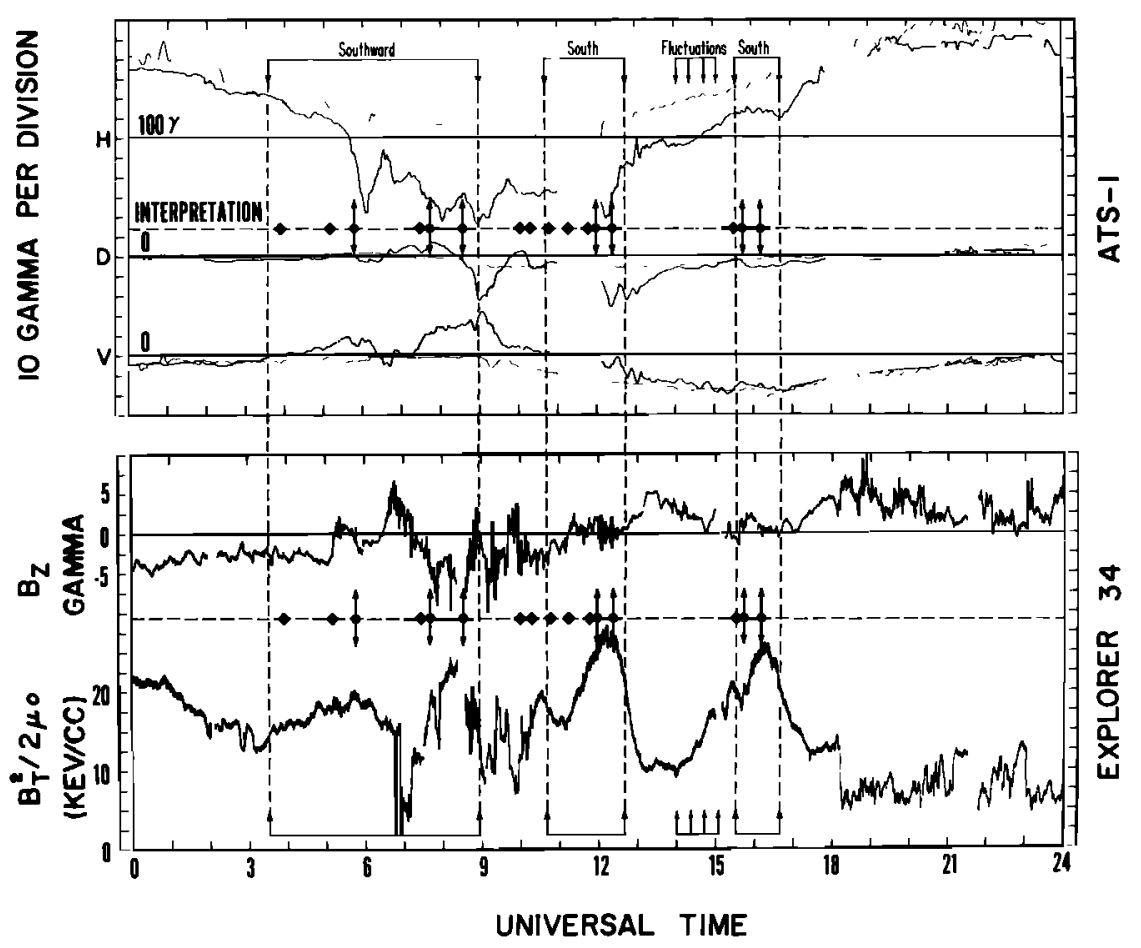

Fig. 18. Magnetospheric magnetic field observations on February 13, 1968. ATS 1 observations at synchronous orbit in top panel and Explorer 34 observations in the geomagnetic tail in bottom panel. Substorm interpretation discussed in text is shown by dashed horizontal lines.

From the data presented above it is easy to see that large changes also occurred in the auroral zone after the onset times chosen from midlatitude magnetograms. The changes are of the form expected from our model, hence the auroral zone data do not contradict it. However, it does not follow logically that since all magnetospheric substorms include a polar magnetic substorm, all polar magnetic substorms imply that a magnetospheric substorm has occurred.

\section{AN EVEN MORE COMPLEX EVENT, MARCH 27, 1968}

As a final example of the complexity of substorm behavior, we have chosen to reexamine the magnetopause erosion event originally described by Aubry et al. [1970]. In the original analysis of this event Russian magnetograms were not yet available and the utility of midlatitude magnetograms had not been recognized. As a consequence, the timing of substorm activity in this report is clearly in error. However, as we will show below, the original conclusions of this work are still justified.

In the work of Aubry et al. successive encounters of the magnetopause were interpreted as inward motion of the magnetopause in response to a southward solar wind magnetic field. The OGO 5 satellite on which the observations were made was inbound near the equatorial plane and in the $0900 \mathrm{LT}$ meridian. By an analysis of the relative amount of time spent in the magnetosphere and magnetosheath the authors arrived at the interpretation shown in Figure 19.

The sloping line in the top of the figure indicates the radial position of OGO 5 . A thick line is shown when the satellite was outside the magnetopause. The dashed line of quasi-sinusoidal form is the inferred position of the magnetopause. Any other trajectory which encounters the satellite path at the appropriate universal times is also an acceptable interpretation. However, as is apparent from the figure, this interpretation is based on an attempt to minimize the complexity of the inferred magnetopause motion. This interpretation is summarized below.

The first "normal" crossing of the boundary occurred at 1700 . About 1710 the magnetosheath magnetic field turned southward. Approximately $20 \mathrm{~min}$ later the magnetopause was observed to move in- 


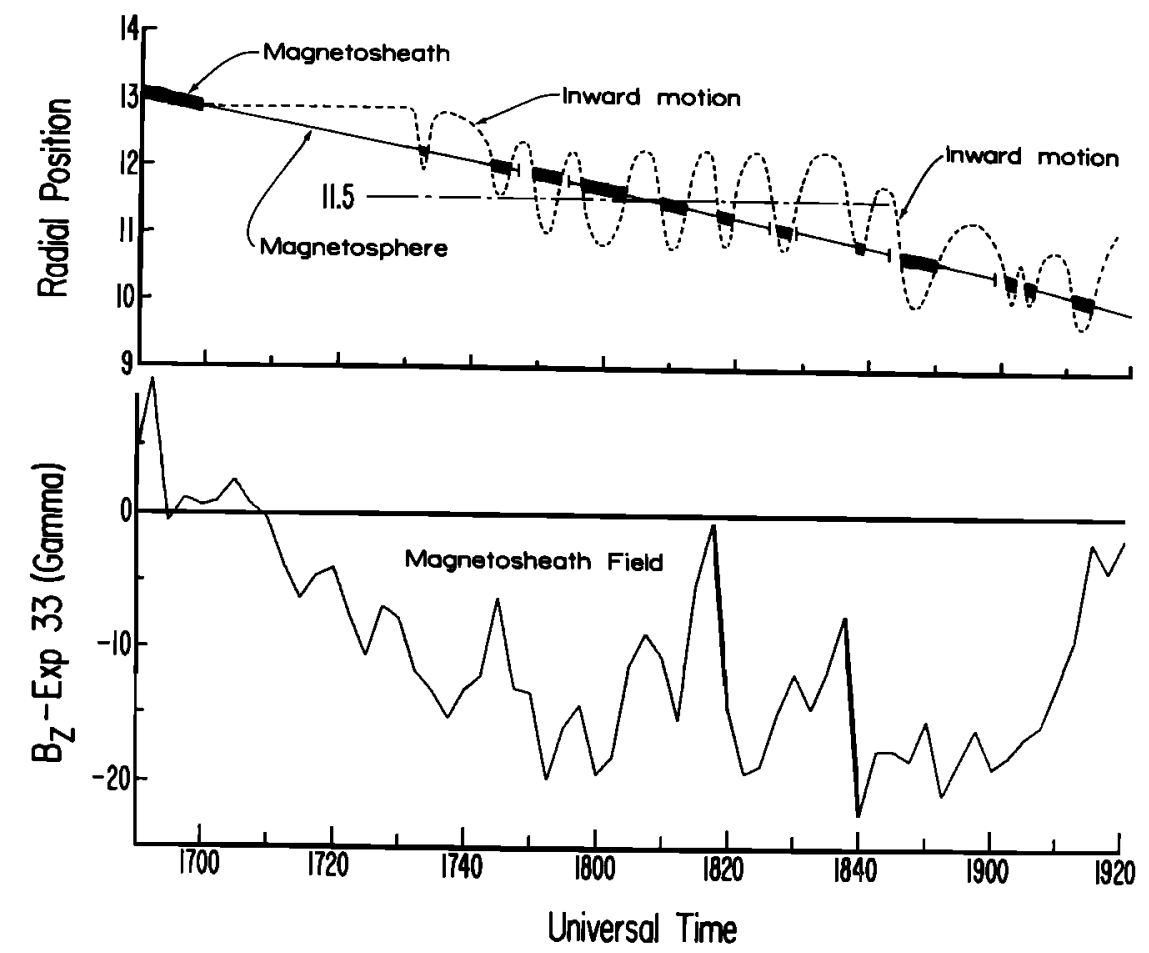

Fig. 19. A schematic representation of an interpretation of OGO 5 magnetic field observations on March 27, 1968, as made by Aubry et al. [1970]. Inward motion of the magnetopause followed a southward turning of the magnetosheath magnetic field.

ward. The boundary briefly passed over the satellite at 1732. Shortly thereafter, it moved inside the satellite and oscillated with fairly constant period about a fixed position at $11.5 R_{E}$. At about 1820 , when the satellite was inside this average position, there was a large fluctuation in the magnetosheath field. After another 15 to $20 \mathrm{~min}$ the boundary again was observed to move inward. The final encounter of the boundary occurred at 1915 , at which time the satellite entered the magnetosphere permanently.

In the analysis made by Aubry et al. [1970] a substorm expansion was identified using an auroral zone station (Sodankyla) at the dusk meridian. The sudden onset of a negative bay began at 1940 . Since the inward motion occurred prior to this time, it was concluded that magnetopause erosion was a growth phase phenomenon.

In the criticism made by Akasofu [1972] it was pointed out that midnight stations should be used for substorm timing. Using such data, he has shown that the expansion phase actually began at 1850 . Thus he concludes ". . . the major inward motion occurred during the expansion phase" (p. 11).
Auroral zone data for this day are plotted in Figure 20. Possible expansion onsets in the auroral zone at the time of the erosion event are shown by stars at 1756 and 1854 . We note that the near-midnight station, Dixon Island (DI), clearly shows a sudden bay onset at 1854, justifying the criticism of Akasofu. We note also that the dawn meridian station, Point Barrow (BW), suggests that a bay began at 1756 . There is additional evidence of this earlier event at the midnight station, Dixon Island. Finally, we note that on the basis of midlatitude magnetograms to be discussed next, 1921 (final vertical dashed line) has been chosen as an onset time for this magnetospheric substorm.

Midlatitude magnetograms for March 27, 1968 are displayed in Figure 21. In order to maximize the available information we have traced the original data rather than plot the few stations for which digital data are available. As shown at the right side of the figure, there is a wide variety of sensitivities at the various observatories. Despite this problem, however, several facts are quite clear. First, 1921 is the onset time for the midlatitude positive bay, particularly near midnight. Second, it appears that a weak posi- 
tive bay did begin in the dawn sector at 1854 (see trace of Gnangara, GN). The Tangerang magnetogram, not shown, is essentially identical to that of GN. Third, there is no midlatitude positive bay onset at 1756 although stations near dusk did record a field maximum.

Solar wind and geomagnetic tail observations on this day are summarized in Figure 22. The interpretation of the tail data is particularly complicated because of proximity to the plasma sheet. The interpretation made by Aubry et al. [1970] is as follows. Starting about 1850, Explorer 34 was inside the plasma sheet and just encountering the thinning boundary. From this time until 1921 the field magnitude increased as the plasmia sheet continued to thin and the satellite passed into the lobe of the tail. Shortly after 1921 the boundary of the plasma reversed its motion and expanded over the satellite.

The $Z$ component of the field also appears to be correlated with the two times determined from the ground magnetograms. Just after 1854 , the time of a possible onset in the auroral zone, the $Z$ component turned negative. It remained negative for approximately $20 \mathrm{~min}$ until the expanding plasma sheet engulfed the satellite at 1921 . Following this, the $Z$ component rapidly increased in magnitude as the total field continued to decrease.

This substorm event on March 27, 1968 is similar to the two discussed in the previous section. Here again there is a clear discrepancy between the onset time determined from auroral zone magnetograms and the onset determined from midlatitude magnetograms. In both cases, the midlatitude data give a later onset than the auroral zone data.

In order to demonstrate that all the observations of March 27, 1968 are consistent with our phenomenological model we need to discuss the plasma sheet thinning in more detail. For the data presented here it appears that thinning began at the location of Explorer 34 at 1854 , which is the time of the auroral zone onset. Expansion, on the other hand, appears to have begun at 1921 , the time of the midlatitude onset. In terms of our phenomenological model the thinning has occurred during the growth phase of the magnetospheric substorm prior to midlatitude onset. However, we should point out that in the terminology of $A$ kasofu [1972], the thinning occurred during the expansion phase of a polar magnetic substorm.

Actually, according to the discussion of Russell and McPherron [1973], McPherron et al. [1973], or Nishida and Nagayama [1973], Explorer 34 is not ideally located to observe plasma sheet thinning during the growth phase. In the phenomenological model outlined by these authors thinning first occurs closer

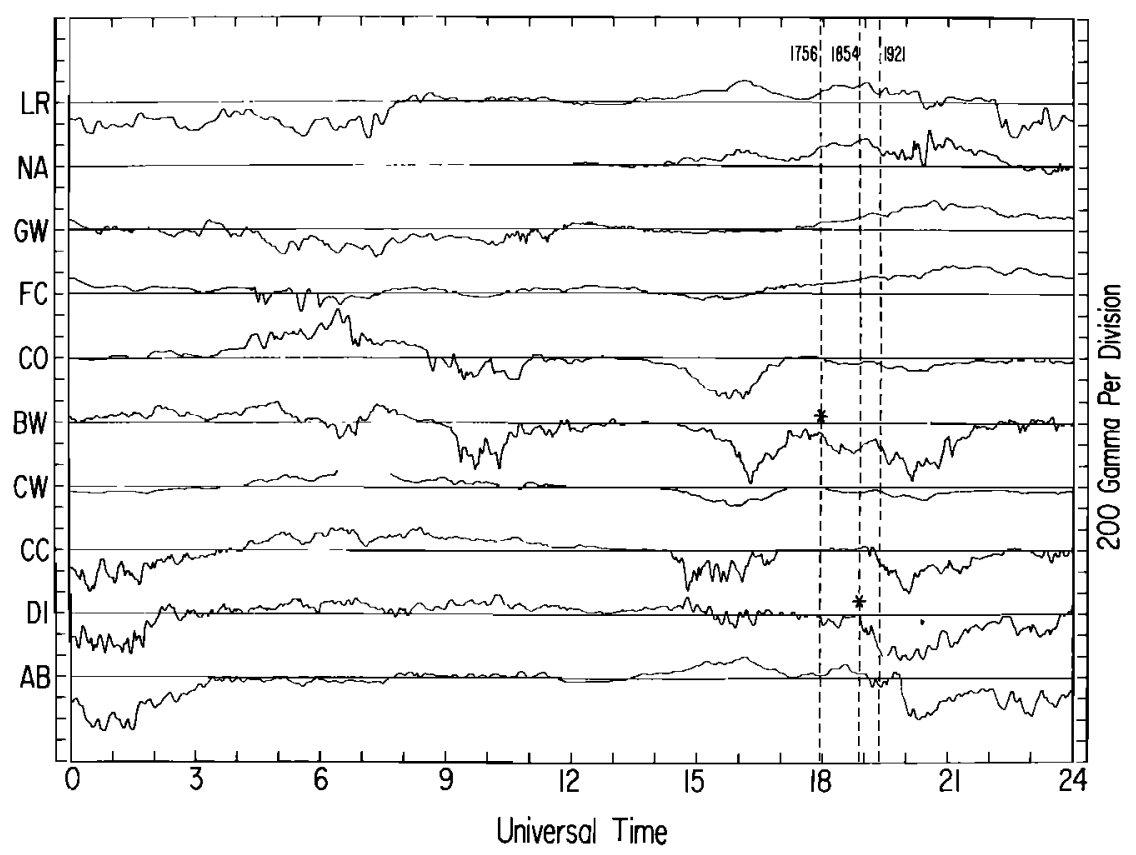

Fig. 20. Auroral zone magnetic field observations of $H$ component on March 27, 1968. Auroral zone onset is at $1854 \mathrm{UT}$. 
to the earth (approximately 10 to $15 R_{E}$ ). A neutral point forms close to the earth and reconnection of field begins. Eventually the neutral point moves away from the earth expanding the plasma sheet behind it as it moves.

The March 27, 1968 data are consistent with this interpretation. The auroral zone onset at 1854 would then be the formation of a neutral point inside of Explorer 34 ( $B_{z}$ becomes negative). The midlatitude onset at 1921 is then the outward motion of the neutral point ( $B_{z}$ rapidly increases, turning positive, and the plasma sheet expands ).

\section{DISCUSSION}

We have shown that some substorms fit our phenomenological model of substorms almost exactly. On the other hand, many substorms are more complex than described by the model. Further, there appears to be a discrepancy between the onset of polar magnetic substorms and the onset of mid-

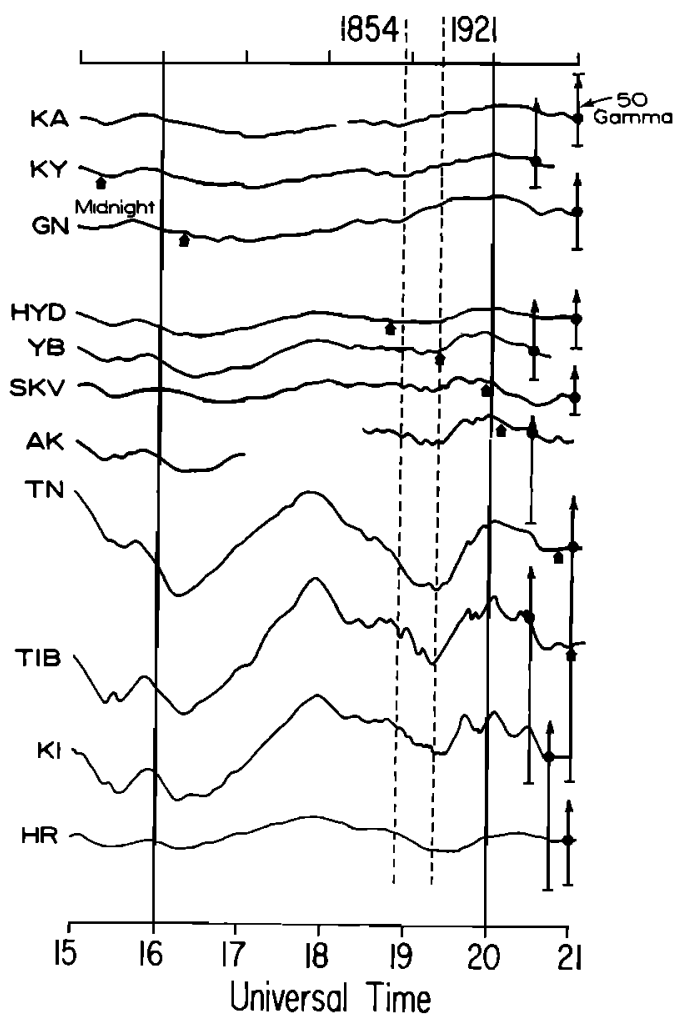

Fig. 21. Midlatitude magnetic observations of $\boldsymbol{H}$ component on March 27, 1968. Midlatitude onset is at 1921. Station designations are, respectively, from the top: Kakioka, Kanoya, Gnangara, Hyderabad, Yangi Bazar, Sverdlovsk, Ashkhabad,

Tananarive, Tbilisi, Kiev, and Hermanus. latitude positive bays. In general, when a discrepancy exists, the auroral zone onset is earlier. However, for the four substorms we discussed in detail we showed that the energy density of the tail was systematically organized by the midlatitude onsets. Caan et al. [1973] and Nishida and Nagayama [1973] have demonstrated this same organization for a much larger sample of substorm events. Consequently, we are of the opinion that the present phenomenological model is correct except that it does not correctly predict when polar magnetic substorms will begin.

In our previous work we have consistently referred to our origin of substorm time as the onset of the expansion phase. However, in much of our work this time is actually the onset of midlatitude positive bays. This terminology was based on observations such as those on February 25, 1967, for which the two times appear to be the same. In some substorms this is not the case. For these, criticism such as that of Akasofu [1972] is clearly justified since "onset of the expansion phase" has a well-accepted definition.

It appears to us that the "growth phase controversy" has been a consequence of these different definitions of substorm onset. When midlatitude onsets are used, the magnetospheric data are well organized by a phenomenological model which includes a growth phase. When auroral zone onsets are used, this is often not the case. In fact, in our opinion, magnetospheric data are not well organized by auroral zone onsets of polar magnetic substorms. For example, using the data shown above, it would be necessary to argue that in some substorm expansions the energy density in the tail lobe increases and in others it decreases. With our assumption that the tail plays a fundamental role in the substorm process, we believe this is physically unrealistic and indicative of an incorrect determination of the time of origin for the magnetospheric substorm.

At the present time, the physical mechanisms causing the auroral zone and midlatitude magnetic signatures are not known. As a consequence, there does not appear to be a good physical reason for choosing one rather than the other in timing magnetospheric phenomena. In fact, recent work by Rostoker [1972] suggests that a polar magnetic substorm is more complicated than described by the model of Akasofu [1968]. In particular, there may be two westward electrojets, one at the southern edge and one at the northern edge of the auroral zone. The temporal development of these two is complicated and not fully understood. Consequently, we 


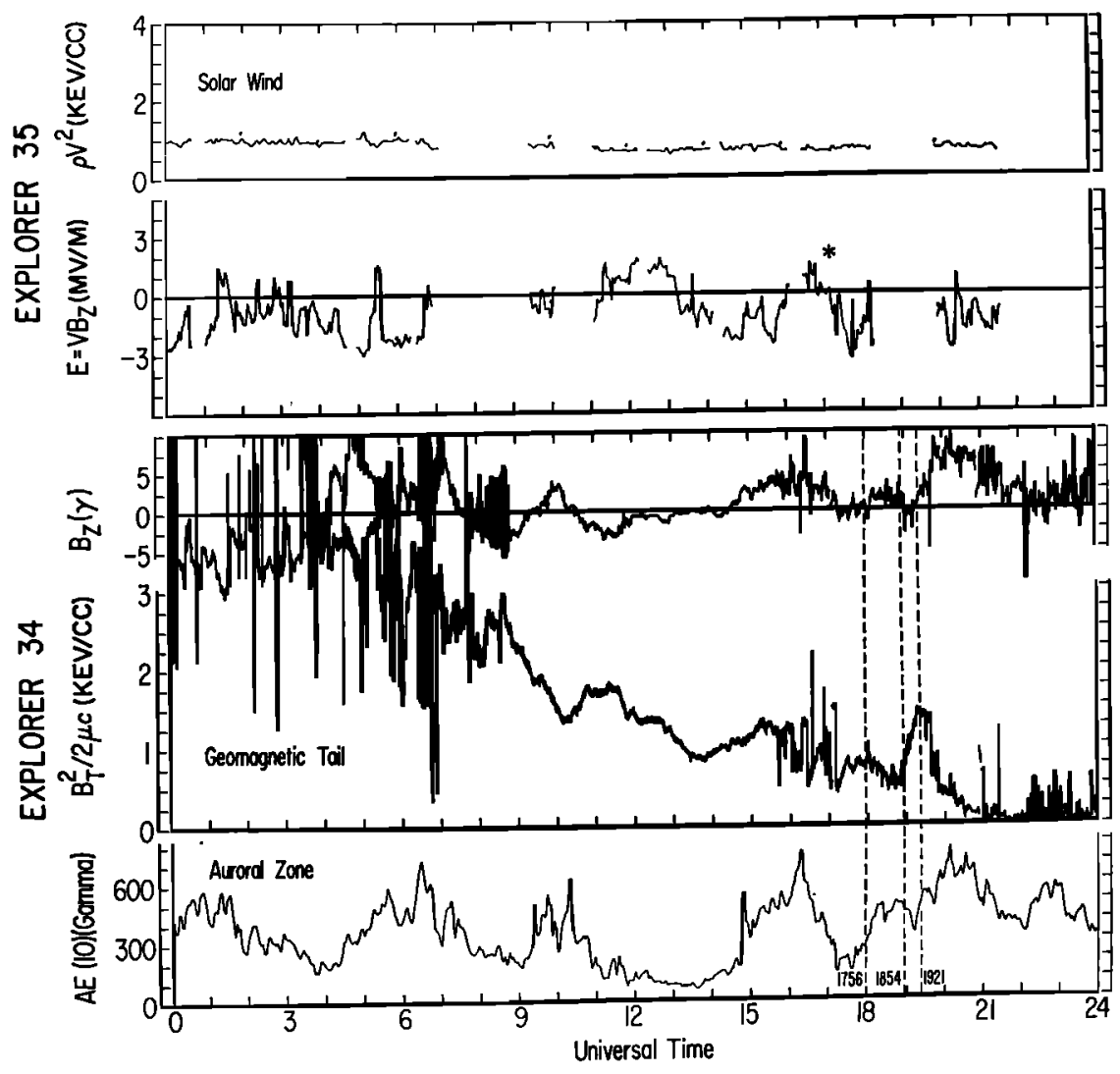

Fig. 22. Solar wind and geomagnetic tail variations on March 27, 1968.

feel that the argument that midlatitude onsets systematically organize magnetospheric data is sufficient justification for using them in our studies of magnetospheric substorms.

\section{INTERPRETATION}

In the preceding discussion we indicated that the growth phase controversy results from two different definitions of the origin of substorm time. Midlatitude onsets appear to support the concept of a growth phase for the magnetospheric substorm. In this section, we consider the question of why this may be the case.

A model current system which has been used by a number of investigators in studies of the westward electrojet is shown in Figures 23, 24, and 25. A portion of the tail current is diverted down field lines, flows westward through the ionosphere and returns up field lines in the evening sector (Figure 23). The perturbation of the tail current required to produce this equivalent current is shown in Figure 24. Magnetic perturbations from this current are shown in Figure 25 for a particular set of model parameters. The north-south component at midlatitudes has a positive disturbance symmetric about the central meridian of the equivalent current system and the east-west component has an antisymmetric disturbance. In the auroral zone the westward ionospheric current dominates and negative bays in the north-south component are produced. At synchronous orbit magnetic perturbations are of the same form as an equatorial station on the earth's surface. Finally, the eastward magnetospheric segment counter to the tail current will reduce the magnitude of the tail field.

Thus, the model current system shown in Figures 23,24 , and 25 produces all of the magnetic perturbations predicted by the phenomenological model during the expansion phase of a magnetospheric substorm. The high degree of correlation between observations in the tail lobe and synchronous orbit and midlatitude positive bays provides considerable evidence of the physical reality of such a current system.

It is important to note that the midlatitude mag- 


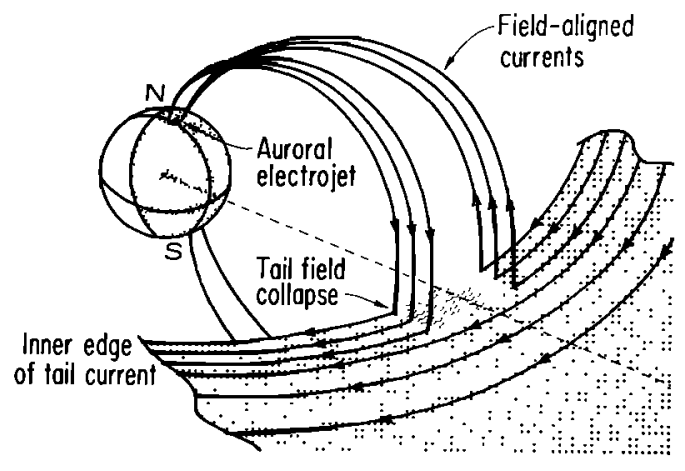

Fig. 23. Dipole field-aligned current model of substorm expansion which can account for expansion phase observations in the tail lobe at synchronous orbit in the auroral zone and at midlatitudes.

netic effects of this current system are directly proportional to its angular extent. In the auroral zone this is not the case. Provided the observations are made under the electrojet, the magnitude of the disturbance is primarily controlled by the current strength. Thus, an explanation of localized polar magnetic substorms may be a field-aligned current system of limited angular extent.

The physical mechanisms which would cause diversion of the tail current are not known. We have previously suggested [Russell and McPherron, 1973; McPherron et al., 1973; McPherron, 1972] that an expansion phase is a consequence of the formation of an $X$-type neutral line close to the earth. Localization of the neutral line in the tail might explain a fieldaligned current system of limited angular extent and a localized polar magnetic substorm.

A schematic view of a localized neutral line is

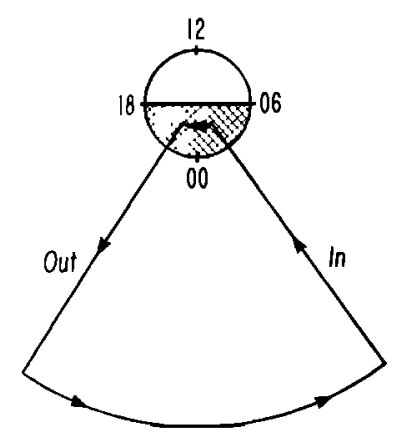

Fig. 24. Magnetic perturbation of the tail current. $70^{\circ}$ wedge, $L=6.0, I=$ $2 \times 10^{6}$ amp.

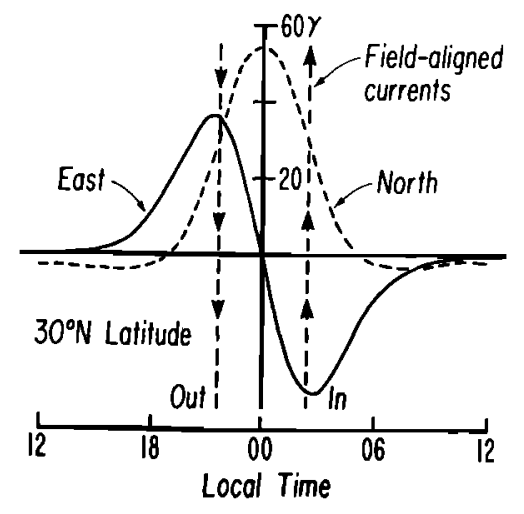

Fig. 25. Dipole field-aligned current model of substorm expansion for a particular set of model parameters.

shown in Figures 26, 27, and 28. In this model the neutral line forms initially on closed field lines within the plasma sheet. Consequently, there is a corresponding $O$-type neutral line. Note that in this model it is assumed that there is a more distant neutral line which defines the plasma sheet boundary between open field lines in the lobe and closed field lines in the tail. From the noon-midnight meridian view shown in Figure 26, it is clear that there is a limited region of southward field between the $X$ and $O$-type neutral lines.

The equatorial view shown in Figure 27 emphasizes the spatial localization of the region occupied by the pair of $X$ - and $O$-type neutral lines. We propose that tail current normally flowing through this region is diverted through the ionosphere in the way suggested by our model current system.

The behavior of the plasma sheet and tail lobe in response to such a localized region of merging is not clear. First, it is important to recognize that merging on closed field lines will not change the topology of the magnetosphere. In particular, since open field lines in the lobe are not involved, the size of the polar cap will not change. Second, it is not obvious what the plasma sheet dynamics would be. It seems likely that above the $X$-type neutral line it might thin, while in other regions it might expand.

Unless merging stops because of a change in boundary conditions or because of some self-quenching process, it will eventually reach open field lines, where boundary conditions and density are different. Thus, lobe field lines will eventually take part in the merging. At this point the topology of the magneto- 
sphere begins to change. If, in addition, the angular extent of the region increases significantly at this point, then the disturbance should become evident at midlatitudes as well as in the auroral zone.

In view of the foregoing remarks we make the following suggestion. The onset of a polar magnetic substorm occurs when a localized merging region forms on closed field lines in the plasma sheet. A midlatitude positive bay begins when the merging first encounters open field lines in the lobe of the tail and, for reasons yet unclear, expands rapidly to include a region of considerable angular extent.

This model of the substorm expansion accounts for the earlier onset of polar magnetic substorms. In addition, it can account for a variable delay between this onset and the beginning of midlatitude positive bays. Furthermore, it would appear likely that this delay would depend in a significant way on the previous history of substorm activity.

We should emphasize that there are probably other causes of field-aligned currents and electrojets than the one proposed here. For example, in our explanation of the growth phase [McPherron et al., 1973], the electrostatic potential associated with convection also causes current systems similar to the one discussed above. In particular, it seems likely that this may be the explanation of electrojets seen at the equatorward edge of the auroral zone.

\section{CONCLUSIONS}

In this paper we have reexamined several substorms previously reported in the literature by our group. In this earlier work it was found that the data supported the concept of a growth phase for the magnetospheric substorm. This analysis has been severely criticized by $A$ kasofu [1972], who argued that substorm expansion onsets were improperly

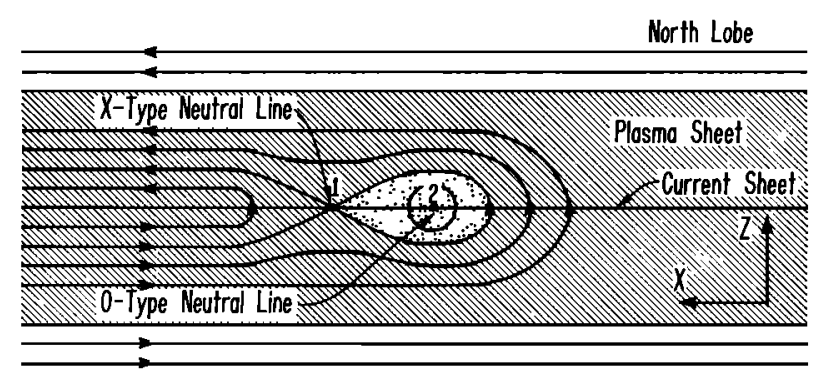

South Lobe

Fig. 26. Schematic drawing of $X$ - and $O$-type neutral lines formed when magnetic field merging occurs on closed field lines inside the plasma sheet: noon-midnight meridian.

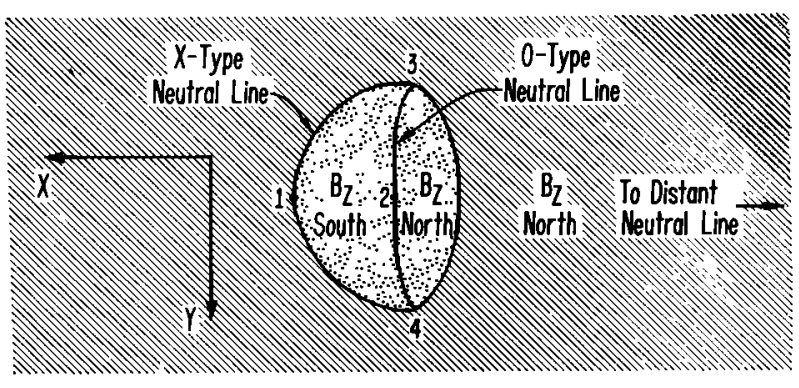

Fig. 27. Schematic drawing of $X$ - and $O$-type neutral lines formed when magnetic field merging occurs on closed field lines inside the plasma sheet: plane of the current sheet.

identified. It is shown above that there is justification for such criticism. In particular, it is noted that our definition of substorm onset is based primarily on midlatitude magnetograms which often give a later onset than determined in the auroral zone. We argue, however, that this is the appropriate time to use, as it makes the magnetospheric signature of substorms more systematic. In our interpretation we argue that a simple model of an ionospheric "short circuit" of the tail current links the ground and magnetospheric observations in the manner suggested by our phenomenological model of the expansion phase. We speculate that the formation of a localized region of magnetic merging on closed field lines may be the reason for the diversion of the tail current. We note, however, that such merging does not alter the magnetospheric topology until it involves open field lines in the tail lobe. Consequently, we suggest that the apparent delay between auroral zone onset and later midlatitude onset may correspond to this distinction in the type of field line involved in the merging process. We emphasize that there may be other causes of auroral electrojets; for example, convection could drive growth phase electrojets.

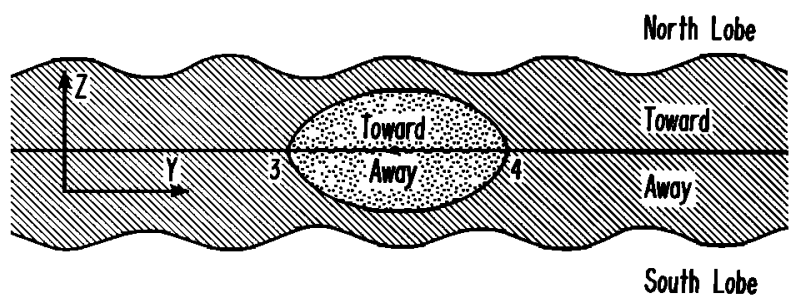

Fig. 28. Schematic drawing of $X$ - and $O$-type neutral lines formed when magnetic field merging occurs on closed field lines inside the plasma sheet: tail cross section. 
Acknowledgments. This work was supported in part by grants from the National Aeronautics and Space Administration (NGL 05-007-004), the National Science Foundation (GA-34148-X), and the Office of Naval Research (ONR N00014-69-4016). The collaboration of M. Caan, R. Clauer, and N. Cline in parts of this work is gratefully acknowledged.

\section{REFERENCES}

Akasofu, S.-I. (1968), Polar and Magnetospheric Substorms, 280 pp., Springer, New York.

Akasofu, S.-I. (1972), Scientific design of a shuttle auroral observatory system, vol. III Rep., 70 pp., Geophysical Institute, University of Alaska, Fairbanks, Alaska.

Akasofu, S.-I., and A. L. Snyder (1972), Comments on the growth phase of magnetospheric substorms, J. Geophys. Res., 77(31), 6275-6277.

Aubry, M. P., and R. L. McPherron (1971), Magnetotail changes in relation to the solar wind magnetic field and magnetospheric substorms, J. Geophys. Res., 76(19'), 4381-4401.

Aubry, M. P., C. T. Russell, and M. G. Kivelson (1970), Inward motion of the magnetospause before a substorm, J. Geophys. Res., 75(34), 7018-7031.

Caan, M. N., R. L. McPherron, C. T. Russell, and N. E. Cline (1973) Statistical analysis of tail lobe magnetic variations and their causes, paper presented at the Chapman Memorial Symposium on Magnetospheric Motions, sponsored by the American Geophysical Union, Boulder, Colo., June 1973.

Clauer, C. R., and R. L. McPherron (1973), Variability of the midlatitude magnetic signature of magnetospheric substorms, paper presented at the Chapman Memorial Symposium on Magnetospheric Motions, sponsored by the American Geophysical Union, Boulder, Colo., June 1973.

Coroniti, F. V., and C. F. Kennel (1972a), Polarization of the auroral electrojet, J. Geophys. Res., 77(16), 28352850.

Coroniti, F. V., and C. F. Kennel (1972b), Changes in magnetospheric configuration during the substorm growth phase, J. Geophys. Res., 77(19), 3361-3370.

Coroniti, F. V., and C. F. Kennel (1973), Can the ionosphere regulate magnetospheric convection?, J. Geophys. Res., 78(16), 2837-2851.
Fairfield, D. H., and N. F. Ness (1970), Configuration of the geomagnetic tail during substorms, J. Geophys. Res., 75(34), 7032-7047.

Heppner, J. P., M. Sugiura, T. L. Skillman, B. G. Ledley, and M. Campbell (1967), OGO-A magnetic field observations, J. Geophys. Res., 72(21), 5417-5471.

Hones, E. W., Jr., J. R. Asbridge, S. J. Bame, and S. Singer (1973), Substorm variations of the magnetotail plasma sheet from $X_{S M I} \simeq-6 R_{E}$ to $X_{S M} \simeq-60 R_{E}, J$. Geophys. Res., 78(1), 109-132.

McPherron, R. L. (1970), Growth phase of magnetospheric substorms, J. Geophys. Res., 75(28), 5592-5599.

McPherron, R. L. (1972), Substorm related changes in the geomagnetic tail: The growth phase, Planet. Space Sci., 20(9), 1521-1539.

McPherron, R. L. (1973), Satellite studies of magnetospheric substorms on August 15, 1968, 1, State of the magnetosphere, J. Geophys. Res., 78(16), 3044-3053.

McPherron, R. L., C. T. Russell, and M. P. Aubry (1973), Satellite studies of magnetospheric substorms on August 15, 1968, 9, Phenomenological model for substorms, J. Geophys. Res., 78(16), 3131-3149.

Meng, C.-I., and D. S. Colburn (1973), Magnetotail variations associated with the southward interplanetary magnetic field, Ser. 14, issue 29, Space Sciences Laboratory, University of California, Berkeley, Calif.

Mozer, F. S. (1973), On the relationship between the growth and expansion phases of substorms and magnetospheric convection, J. Geophys. Res., 78(10), 17191722.

Nishida, A., and N. Nagayama (1973), Synoptic survey for the neutral line in the magnetotail during the substorm expansion phase, J. Geophys. Res., 78(19), 37823798.

Rostoker, G. (1972), Polar magnetic substorms, Rev. Geophys. Space Phys., 10(1), 157-211.

Rostoker, G., and J. L. Kisabeth (1973), The response of the polar electrojets in the evening sector to polar magnetic substorms, J. Geophys. Res., 78, in press.

Russell, C. T., and R. L. McPherron (1973), The magnetotail and substorms, Space Sci. Rev., in press.

Vasyliunas, V. M., and R. A. Wolf (1973), Magnetospheric substorms: Some problems and controversies, Rev. Geophys. Space Phys., 11(1), 181-189. 